\title{
Subjective Social Status in Transitioning China: Trends and Determinants*
}

\author{
Forthcoming in Social Science Quarterly \\ Yunsong Chen \\ Department of Sociology \\ Nanjing University \\ yunsong.chen@nju.edu.cn \\ Mark Williams \\ Department of People and Organisations \\ University of Surrey \\ m.t.williams@surrey.ac.uk
}

\begin{abstract}
Objective: This study provides the first representative portrait of temporal trends in subjective social status (SSS) in China. SSS has been shown to be important for health and wellbeing outcomes, yet little is known how its determinants change over time. Methods: Using data from 10 nationally representative survey waves 2003 and $2012(\mathrm{~N}=80,141)$, we examine descriptive and multivariate trends. Oaxaca-Blinder decomposition is used to decompose changes in determinants of SSS over time. Results and Conclusion: Results demonstrate that (1) average SSS has risen over time, yet there is an enduring tendency for the Chinese to place themselves in lowest levels in the social hierarchy; (2) objective socioeconomic variables such as income explain much of the rise in average SSS; (3) yet the strength of the relationship between socioeconomic variables predicting SSS has been weakening over time. This article adds to our understanding of the determinants of SSS in contexts undergoing transition.
\end{abstract}

Key words

Subjective social status; status discordance; China

Word count

8,043 (including endnotes, tables, and figures)

*Yungong Chen is the corresponding author. All data and replication code available from the corresponding author. 


\section{Introduction}

With a tradition stemming back to Marx, Weber, and Durkheim, sociologists have long been interested in where people locate themselves in the social hierarchy. A large literature has since been devoted to understanding the determinants of the closely-related concepts of subjective social status (SSS), subjective social class, and class identification. Empirical findings demonstrate that self-rated status is strongly related to - but does not necessarily always coincide with - objective markers of social position such as education, income, and occupation. A common finding in this literature is the tendency for people in Western societies to overwhelmingly express a middle-class identity irrespective of their relative objective social position (Centers 1949; Hodge and Treiman, 1968; Jackman and Jackman, 1983; Wright and Singelmann, 1982; Evans et al., 1992; Kelley and Evans, 1995; Oddsson, 2010; Hout, 2008). More recent studies have begun to examine cross-country variation in the subjective social status structure across countries and has factors such as national wealth and income inequality matter for the distribution of SSS across countries (Evans and Kelley, 2004; Andersen and Curtis, 2012; Surridge, 2007; Curtis, 2014). Understanding what determines SSS is important, as a large body of work has consistently shown self-placed social position is a strong determinant of physical and mental health, independent of material measures of social position (e.g. Adler, Epel, Castellazzo, et al., 2000; Singh-Manoux, Marmot, Adler, 2005; Kim, Lee, et al. 2014). This implies that the effects of economic development on the wellbeing of a society is contingent on its social consequences. Indeed, feelings of SSS have been shown to predict levels of trust, pro-social behavior, and engaging in unethical behavior (Piff et al. 2010; Piff et al. 2011) at the individual-level, and to have consequences for social cohesion at the country-level (Hamamura 2012). Thus SSS and its over time changes has important implications for aggregate wellbeing and cohesion, potentially moderating the effects of economic development.

Country-specific studies on the determinants of SSS have tended to focus on relatively stable Western societies, but some studies have been conducted on a small number of Asian societies with well-established markets (Shirahase, 2010; Nam, 2013; Goldman et al., 2006). Few of these studies have examined how the structure of SSS changes over time as countries develop, particularly cases where the development was relatively rapid. Several studies on transforming societies in Eastern 
Europe countries exist but are limited to the early 1990s, following the collapse of communist regimes (Evans et al., 1992; Evans and Kelley 2004). Although contemporary China provides a sociologically interesting opportunity to explore the distribution, determinants, and discordance of self-rated status during a period of rapid social transition, studies are scarce. The few China-focused studies on SSS are based on unrepresentative samples of specific demographic groups or certain cities and are based on single-year cross-sections, meaning that the findings are neither generalizable nor sufficient to track the temporal trends during a sociologically-interesting period of rapid urbanization and economic development (Zang, 2012; Zhou, 2011; Liu, 2001; Gao, 2013; Li et al., 2005).

This study complements the existing literature by systemically documenting SSS in China over the decade 2003 to 2012 using 10 waves of the nationally-representative Chinese General Social Survey (CGSS) and the Chinese Social Survey (CSS). China provides a sociologically interesting case for testing the theories about how SSS is shaped and evolves owing to the rapid economic and social changes over a relatively short period of time. In this article, we present the first representative portrait of SSS in China, examining its distribution and determinants, and most importantly, its evolution, through a period of rapid economic and social change.

\section{Subjective Social Status: Theory and Evidence}

A host of individual-level and contextual-level factors have been found to shape perceived status and so the subjective status structure (Hodge and Treiman, 1968; Guest, 1974; Morris and Murphy, 1966; Lopreato and Hazelrigg, 1972; Jackman and Jackman, 1973; Wright 1985). Evans and Kelley (2004) classified theories into the relationship between these objective social positions and SSS into three main strands. The first strand, labelled the "reality argument", stemming from the ideas of Marx and Durkheim states that SSS is a direct reflection of one's objective position in the social hierarchy. Thus the basic hypothesis is that differences in economic development and political systems across countries, as well as changes over time within them, should be reflected in the distributions of SSS. In particular, as Evans and Kelley (2004) surmise, Marx expected a growing polarization in the distribution of self-placed status, while Durkheim foresaw the middle strata to grow, along with their divergent predictions for the trajectory of industrial societies. 
The second strand, labelled the "reference group argument" stresses that SSS is influenced by a "referent other" based on subjective local sampling, and so reflects one's position in one's immediate social environment (Stouffer et al., 1949; Woelfel and Haller, 1971). Since perceptions of social position are made in light of reference groups that are composed of fairly homogeneous social networks with whom frequent interaction occurs, the vast majority will perceive themselves to be somewhere in the middle, with much smaller groups placing themselves at the tails of the social hierarchy, irrespective of more objective indicators of social status. Given this human propensity for rating oneself in relation to a reference group, temporal trends in SSS might not therefore not be expected to move in line with the economic development and the distribution of more objective measures of social positions, as broader trends will affect one's reference group in a similar way to oneself, such that the majority of people will always see themselves as somewhere in the middle.

The third strand, the reference group and reality stand, which is labelled the "R\&R-blend" (Kelley and Evans, 1995), is a mixture of the preceding two theories, incorporating both "the social-psychological forces towards centrality and the social economic forces towards dispersion" (Evans and Kelley, 2004:4). This argument claims that that changes in the distribution of SSS in a societies does occur, but it is modest and gradual over time, reflecting both shifts in the objective status structure and in subjective reference groups.

To what extent are these theories supported by empirical studies? In general, previous findings reassuringly suggest that most people do in fact understand social position labels (Jackman and Jackman, 1983) and routinely place themselves on a certain rung of the social ladder (Centers, 1949; Moorhouse, 1976; Wright, 1985; Evans et al., 1992). Numerous studies across many countries have revealed that people of all economic backgrounds tend to see themselves as being positioned in the middle strata (Evans et al., 1992; Evans and Kelley, 2004; Adair, 2001; Hout, 2008) and so SSS may be viewed more as an indicator of psycho-social identity (Adair, 2001). Although objective social position, in particular education, income, and occupation, play a remarkably stable role in forming SSS, particularly in the United States (Hout, 2008), they do not perfectly predict self-placement in the social hierarchy (Hodge and Treiman, 1968; Kelly and Evans, 1995; Oddsson, 2010). In addition, aside from individual attributes, contextual effects such as the role of the national economic 
development, income inequality, employment structure, and prevailing political ideology are all found to be significant in shaping SSS across countries (Evans and Kelley, 2004; Andersen and Curtis, 2012; Curtis, 2014).

Overall, then, the literature broadly supports the "R\&R blend" in that perceived status is related to objective indicators - but the relationship is not perfect - as people (in Western societies) have a tendency ("bias") to place themselves somewhere in the middle. Moreover, the few over time studies find that the relationship between objective indicators such as education, income, and occupation have a remarkably stable relationship with SSS over time, even though their structures have changed in most countries. This could partly be due to the relatively gradual change in the educational, income, and occupational structures in economically advanced Western countries over the span of years SSS data are available. What is lacking in the literature is an examination as to how the connections between objective indicators of social position and subjective ratings of social status change over time within countries, particularly in a context where economic structures have changed rapidly enough in the time span for which data are usually available. China provides a good case study to do this.

\section{SSS in Contemporary China}

Despite some prior SSS studies in other parts of Asia (Goldman et al., 2005; Kikkawa, 2000; Shirahase, 2010; Nam, 2013), few empirical studies devoted to perceived status have provided a systematic account for China. The literature is fairly small and tends to be based on either specific demographic groups or cities using single cross-sections. In the Mainland Chinese literature, Liu (2001), for instance, only analyzed urban residents in Wuhan City to study the discordance between objective and subjective social status. Li et al. (2005), in another example, limited their research to urban residents in major provincial capitals to study the same topic. Gao (2012), examining six cities, provided tentative evidence of the decline of SSS on a sample of urban residents. Outside of the Mainland Chinese literature, the dearth of Chinese studies and the problem of unrepresentative samples is even more salient. For instance, Zhou (2011) focused on Shanghai residents to explore how new media-use affects perceived status. Zang (2012) exploited the data drawn from Ürümchi City to examine how urban Uyghurs perceive themselves in the social hierarchy. 
Since SSS can be viewed as a psycho-social reflection of objective positions, China provides an interesting case in its own right because the distribution of objective positions on the social ladder have greatly changed in character and subjective reference groups may have been complicated by this process of rapid industrialization and urbanization. ${ }^{1}$ For example, urban residents earn more, and are better educated than those remaining in rural areas, but they are perhaps more likely to place themselves at the bottom of society simply because their reference are other urban residents who have more varied earnings and education than rural residents. Likewise, rural-urban migrants may also report lower status than rural residents simply because their reference groups have changed from village to urban neighbors. These are in fact the Chinese versions of Yoshino's merchant seaman, referred to as status discordance or ambiguity in the classic study by Hodge and Treiman (1968), and are perhaps more complicated simply because of the vast scale and accelerated pace of the social transition. Understanding the determinants of aggregate-level SSS is important for any society, with China being no exception, because SSS is an independent determinant of wellbeing and social cohesion at the individual and societal levels (Adler, Epel, Castellazzo, et al., 2000; Singh-Manoux, Marmot, Adler, 2005; Kim, Lee, et al. 2014; Hamamura 2012).

Of the three theoretical strands outlined by Evans and Kelley (2004), what would we expect to be happening in China with respect to temporal trends in SSS? The "reality argument" would predict that as Chinese society develops economically, with a growth in educational attainment, income, and an expansion in higher status occupations, average SSS should rise over time in line with such development. The "reference group argument" would predict that changes in these objective positions would have little effect on the aggregate SSS structure, because evaluations of social positions are made with reference to homogenous groups that experience similar economic and social advancement due to homophily. The "R\&R blend argument" would predict that, with economic development comes a shift in the SSS structure too, but that this would be more modest than changes in more objective positions such as educational expansion or rising incomes. In what follows, we investigate which of these three predictions best describes contemporary China.

\section{Data and Analytical Strategy}




\section{Data and Sample}

Data comes from two nationwide survey projects: the Chinese General Social Survey (CGSS) and Chinese Social Survey (CSS). The CGSS was initiated by Hong Kong University of Science and Technology and Renmin University in 2003, and have been jointly conducted together with several leading universities in China annually or bi-annually ever since. The CSS was initiated in 2006 by the Chinese Academy of Social Sciences and repeated in 2008 and 2011. Each wave of the CGSS sampled 5,000 to 12,000 households, drawn from 125 counties in around 30 provinces, whilst each wave of the CSS sampled 7,000 to 8,000 households, from 128 counties in around 30 provinces. Although the two projects are conducted by different institutions, they are both repeated cross-sections using very similar multi-stage stratified national probability sampling, and share key questions with identical wording, answer categories, and sequencing. As such, they are comparable.

[Table 1 about here]

As shown in Table 1, three waves come from the CSS (2006, 2008 and 2011) and seven from the CGSS $(2003,2005,2006,2008,2010,2011,2012)$, giving a total sample of 82,823 Chinese adults. ${ }^{2}$ Amongst them, 80,958 respondents explicitly answered the question on subjective status, representing a 3 per cent item non-response rate. ${ }^{3}$ The 80,958 cases who reported SSS resided in all 31 provinces in mainland China. Around 41 per cent resided in rural areas, with around 59 per cent from urban areas, as urban residents were oversampled. ${ }^{4}$ In addition, given the sampling design of CGSS and CSS, respondents were selected from households with different numbers of adults. Therefore, for each wave we use sampling weights to compute representative figures for the annual general population in China. Finally, considering that the annual sample sizes are different from the real annual population in China from 2003 to 2012, we further use sampling weights to correct for this. ${ }^{5}$ Case weight methods are applied for both descriptive statistics and model estimation. Due to missing values on the variables used to compute the sample weights, our descriptive sample size in 
Figure 1 shrinks slightly to 80,141 (i.e. a further 1.1 per cent).

\section{Survey Instruments}

The 10 waves of the CGSS and CSS asked respondents to explicitly express their SSS by choosing a position on an ordered hierarchy of social positions. There are some discrepancies in how this question was asked. The CGSS switched to a 10 -rung ladder from $2008,{ }^{6}$ whilst the CSS and all other waves of the CGSS (2003-2006) adopted the conventional five-level scale (upper, upper middle, middle, lower middle, and lower level). For compatibility we transformed the 10-rung ladder into the five-level scale for those CGSS years. ${ }^{7}$ In addition, the CGSS 2003 asked the respondents to choose the position of "your family", whilst all the other waves used the wording "yours" for position. Although intuitively the two are compatible, it is problematic to simply merge them for a time-series analysis if the data show considerable divergence. Fortunately, the CGSS 2005 and 2006 asked both questions about family and individual SSS. Comparing the two differently-worded items reveals that 92 per cent of the sample declare exactly the same level to both questions, with a 99.7 per cent concordance when using the less detailed three-level scale.

\section{Analytical strategy}

The analysis proceeds in three steps. In the first step, we descriptively analyze aggregate SSS, before proceeding to examine trends across groups and time. In the second step, we model determinants of SSS in a multivariate way. Because we pay close attention to the effects of objective social status indicators, in particular education, income, and occupation, we exclude those who had never worked from the regression analyses as they have no information on these variables ${ }^{8}$, producing a total working sample of 76,946 cases. Due to missing values on key individual variables, our sample for the multivariate regression finally ends up at 68,054 individuals residing in all 31 provinces, a reduction of $9 \%$. The hazard of missing data is not significantly correlated to major demographic factors such as gender, education, age, income, occupation, and province, meaning that the differences between our sample and the original sample should not bias the subsequent analysis.

We recalculate the sampling weights for these cases and present the descriptions of variables 
used to regress on SSS in Table 2. The three key independent variables of interest are family income (the logarithm of deflated RMB), schooling years, and international socioeconomic index (ISEI) which is based on reported occupation..$^{9}$ Demographic control variables include gender, age, marital status (married, divorced/widowed, single), employment status (employed, unemployed, retired), and residential status (rural or urban).

[Table 2 about here]

Because the data are combined from 10 waves of surveys spanning 10 years and from two different projects, we include year dummies and project dummies ( $1=$ CGSS, $0=\mathrm{CSS})$. To test for trends in the relation between subjective status perceptions and objective conditions such as education, income and occupational prestige, we incorporate a linear time trend and interact this trend with variables of interest in some models. Furthermore, we control for province fixed effects in all models. Although SSS is a categorical variable, we start by fitting an Ordinary Least Square (OLS) model to treat SSS as a continuous variable. This is necessary because our models incorporate interaction terms, and the estimated coefficients of an interaction term in a non-linear analysis can be misleading (Wooldridge, 2002). We still fit Ordered Logistic (OLogit) models since different social strata represent unequal intervals on an underlying social hierarchy, but interactions must be interpreted with caution. ${ }^{10}$ Finally, given the nested nature of the data, we use cluster standard errors on province. $^{11}$

In the third step, we more explicitly model changes in the determinants of SSS over time using the Oaxaca-Blinder decomposition method. This method is conventionally used in the economic analysis of wage gaps between groups (e.g. the gender wage gap). The method decomposes the average difference between male and female wages, for example, into those factors due to "endowments" and those that are due to differences in "returns to endowments". The "endowment effect" is the portion of the gender wage gap due to differences in "endowments" between men and women, such as differences in occupation (for example women might be less likely to work in higher paying occupations such as managers). The "returns to endowment effect" is the portion of the wage 
gap due to differences in how "endowments" are rewarded (female managers may get paid less than their male counterparts). The Oaxaca-Blinder decomposition method can be applied to changes in mean SSS between two time points to decompose changes in mean SSS into those due to shifts in objective social positions such as income ("endowments") and those due to changes in the strength of the association between these variables and SSS ("returns to endowments"). It therefore gives us a handle on the extent to which over time changes in aggregate SSS are due to changes the growth in education, incomes, and higher status occupations, and the extent to which it is due to changes in the strength of the relationship between these variables predicting SSS. In other words, it allows us to apportion changes in average SSS over time into those due to changes in the quantities of objective social positions and the influence of these positions in determining feelings of status.

The "reality argument" would predict that with the expansion of higher education, rising incomes, and expanding higher status occupations would explain most of the change in SSS in China (i.e. "endowments"). The "reference group" argument, on the other hand, would predict shifts in the economic structure will have little or no impact on the SSS structure. If a modest change in the SSS structure is found, any "endowment effect" would be more than completely offset by corresponding shifts in subjectively-defined reference groups such that the relationship between objective indicators would weaken over time i.e. the "returns to endowments" would weaken over time. The "R\&R blend" would predict changes in the economic structure will increase average SSS, but that these will not completely explain shifts in SSS and with some of the shift in over time SSS coming from a shift in the relationship between these objective indicators and perceived status.

\section{Results}

\section{Overview of SSS in China}

As Figure 1 shows, around 40 percent of Chinese see themselves as positioned in the middle strata in the social hierarchy, while around 53 percent locate themselves in the lower middle or lower strata, with fewer than 7 percent in the upper middle or above. This therefore shows that the majority of Chinese do not see themselves being in the center of the social ladder, but towards the lower end. 
[Figure 1 about here]

Since the distribution is not very polarized, we also use the mean score to provide a useful summary of the unimodal distributions. The mean score of SSS is 2.34 , which is highly consistent with other survey evidence on China, ${ }^{12}$ with a standard deviation of 0.90 . To see if this pattern varies over time, Figure 2 presents the distributions of SSS 2003 to 2012. As illustrated in the bar chart, the time trend in the annual mean score shows that SSS among the Chinese slowly increased over the decade. In addition, although middle strata membership ranges from 34 to 43 per cent across years, representing the largest subjective strata overall, the lowest two strata combined account for a larger share, revealing a general tendency for the Chinese to place themselves on the lower rungs of the social ladder. In almost every year, more than 50 percent of the sample expressed a lower or lower middle strata identities. Again, this finding is noteworthy because the existing literature has generally demonstrated that the patterns of how people position themselves in the social ladder in most countries are similar, in that there is a pronounced tendency towards the middle strata. However, these figures reveal that in China, the tendency is to place oneself on lowest social rungs.

[Figure 2 about here]

\section{Overview of SSS across groups}

We next shift our attention to the distribution of SSS within social groups defined by ascribed or attained factors. ${ }^{13}$ Although not presented here, we find that on average women, younger, single people, and urban Chinese, all tend to declare higher status. Overall, except for five subgroups (younger than 35 , tertiary education, $1^{\text {st }}$ income quartile and occupational prestige scores, and Chinese Communist Party members), all the other subgroups demonstrate a prevailing downward tendency: more than half of respondents reported being in the lowest two strata. Even in the $1^{\text {st }}$ quartile of income and occupational prestige group, more than 30 percent of respondents self-rate themselves as lower or lower middle strata. In general, the downward tendency of SSS is pervasive across social groupings. Conversely, even within the lowest subgroups for income, education or prestige, there we 
find evidence of some people declaring themselves in the upper strata, revealing the presence of status ambiguity, as has been found in other countries elsewhere. Nonetheless, such variation within and between groups could disguise important over time trends.

We use the mean score of SSS to examine whether the distributions across subgroups are stable over time. In Figure 3 we present the situation of SSS across social groups defined by objective status indicators over the decade. Specifically, membership of the CCP, which is a proxy of political resources, is associated with a clear and stable SSS advantage. The difference of SSS between different levels of educational attainment, occupational prestige quartiles, and household income quartiles are all pronounced: the mean score increases monotonically with education, income, and occupational status. However, the tendency of convergence amongst the status curves of education and income is seemingly considerable, suggesting that the effects of the two objective factors on SSS may have decreased over the decade. That being said, to explicitly identify the role of each of these factors and their relation to the theories outlined above, we need to conduct multivariate regression analyses to exclude confounding factors before formulating any conclusions.

[Figure 3 about here]

\section{Determinants of SSS}

As Table 3 shows, other things being equal, men report a slightly lower SSS than women, and the elderly have higher SSS than younger people. Married people see themselves as being of a higher social strata than those who are divorced, widowed, or single. As expected, CCP membership, residential status and employment status all matter for SSS in China, holding other variables fixed. Consistent with previous findings in various countries, the results from Table 3 demonstrate that the roles of education, family income, and occupational prestige are all significant and positive when controlling for other factors. As Figure 4 demonstrates, there is substantial variation across groups. Taking education and occupational status in the OLS models as examples, the advantages brought by five more years of schooling (e.g. a postgraduate relative to high school leaver) or a difference of 20 more points on the ISEI scale (e.g. a farmer relative to a maintenance worker) are both around 
0.1-0.12. These are roughly comparable to the difference between being employed and unemployed, or between a CCP member and a non-CCP member, or a married person and a divorced one. This suggests that the objective status indicators of education, income and occupation may not be the only predictors of SSS, consistent with previous findings in other countries, but they do have a very strong bearing on SSS.

[Table 3 about here]

Given the huge socioeconomic disparities between urban and rural areas in China, we include a dummy denoting rural/urban residential status, and interaction terms of objective indicators and residential status. From Table 3, it is clear that rural residents actually express higher SSS than their urban peers, once controlling for other factors, in contrast to the simple descriptive analysis above. This finding suggests that "reference group argument" is pertinent in China, at least in cross-section. Rural residents have a more restricted social milieu relative to urban residents, and are generally less educated and poorer. The significant coefficients of the interaction terms of family income show that the effects of income differ between rural and urban China, with stronger effects in rural China, again emphasizing the role of the "reference group argument" in rural relative to urban areas. However, the roles of education and occupation are more ambiguous (OLS and OLogit model yield different results).

\section{Determinants of SSS over time}

Turning to over time trends, Models 2 and 4 extend Models 1 and 3 by a introducing a linear time trend and interactions with the objective status indicators. As the time trends in the two models both show, during the ten years, there is an upward trend in SSS, even controlling for changes in underlying determinants such as rising incomes and education. This time trend may indicate fundamental changes at the macro level, such as the general economic development of China. In terms of the time trend interactions, we find that that the roles of family income and education on SSS decreases over time as revealed by the negative interactions. For example, in Model 2, although the 
average partial effect for schooling years is 0.019 , the magnitude of the effect declines roughly 0.001 per year over the decade. Assuming a linear trend, the boost to SSS by an additional year of education is half what it was at the end of the decade than what it was at the start. This finding is quite different with what has been reported for other countries. For example, Hout (2008) reports that the effects of education on SSS in American has actually been very stable over the last 30 years. In sum, as expected, clear effects are found for the time trend reflecting wider economic development shaping SSS, as predicted by the "reality argument", but the effects of these factors stemming from the development such as income and education, are getting weaker over time, suggesting a possible mitigating role for "reference group argument".

We next turn to the Oaxaca-Blinder decomposition results in Table 4. Average SSS increased by .34 units between 2006 and $2012 .{ }^{14}$ The results show that .21 or around two-thirds (.21/.34) of the increase in SSS between these two years are due to changes in the levels of the independent variables (i.e. the "endowments effect"). Changes in the strength of relationship between the independent variables and SSS account for about one-third (i.e. "returns to endowments"). Thus on the face of it, it seems that changes in objective indicators of social position have account for most of the change in aggregate SSS, with changes in the strength of them in determining social SSS being less important, although still playing a sizeable role.

To better understand how this result relates to the accounts in the evolution of how SSS is shaped, we next examine the contribution of specific variables to these trends. Table 4 shows the contribution of selected objective indicators of social position that account for the increase in aggregate SSS to reveal which factors contribute towards the overall trends. Family income is found to be the most important variable. The increase in average family incomes alone accounts for almost all the increase in social status (.22/.34). Thus rising incomes are found to be a key determinant in an upward drift in self-rated status. Interestingly, education and social status (derived from occupation) are found to have virtually no explanatory role. This could be because the educational and occupational structures have not upgraded as much as the income structure. Thus, on the face of it, these results demonstrate that changes in SSS in China reflect the "reality perspective" - rapidly rising incomes have led to feelings of higher perceived status. 
[Table 4 about here]

At the same time, the relationship between income and education appears to be becoming a weaker predictor of social status over time, as indicated by the negative signs of the interaction with the linear time trend in Table 3. Table 4 demonstrates however that "returns to endowments" played a lesser role in terms of overall changes, even if their effects on determining SSS are weakening. Examining the subcomponents of the "returns to endowments", we do find that the predictive strength of household income on SSS grew over time, having some explanatory role, its overall contribution the change in aggregate social status is modest compared to the general rise in average incomes which explain most of the rise in SSS.

In further analysis (not shown), we examined several alternative interpretations to rising average incomes explaining most of the rise in Chinese SSS during the 2000s. ${ }^{15}$ Specifically, we investigated whether the above findings could be masking a story relating to increasing income inequality in China, in particular, a growth in the incomes of the business and political elite, as having a role in changes in Chinese SSS over time. Western research has demonstrated that country-level inequality negatively affects SSS (Anderson and Curtis 2012), implying that inequality could provide one route by which shifts in incomes play a key role in accounting for over time changes in the structure of SSS in China. In supplementary analyses, we found that province-level growth in GDP per capita, GINIs, and 90-50 and 50-10 decile ratios do not predict SSS however. The time effect in Table 3 still remains positive and significant but does not diminish in magnitude when inequality indices are introduced to the models. This suggests that the interpretation that the national-level rise in average incomes that increased average SSS in China in the 2000s to 2010s is the more accurate one.

\section{Conclusions}

Little is still known about how the Chinese locate themselves on the social ladder. In this study, we pool 10 waves of nationally representative data to provide the first portrait of trends in SSS in China 
2003-2011. Two key findings emerge. First, there is a tendency of the Chinese to position themselves in the lower strata and not the middle strata, which tends to be the case in Western societies. Throughout the recent decade, more than half of the Chinese see themselves as being located in the lower or lower-middle rungs of the social ladder. Even amongst the richest and those with highest status jobs, more than one third report belonging to the lower or lower middle strata. Thus, if there are persistent "socio-psychological forces towards centrality" in the US and Europe (Evans and Kelly 2004), in China we find that this does not apply. If there is any prominent "socio-psychological force" in China, it is a downwardly one.

Second, we reveal that even with this Chinese downward "bias" in SSS, aggregate SSS has been increasing over time. Rapidly rises in absolute incomes are found to explain almost all of this rise in SSS. The over time shifts in SSS therefore reflect wider national-level economic development over this period, supporting the notion of the "reality perspective" that the SSS structure and its evolution do reflect and co-evolve with national socio-economic conditions. However, coupled with the fact that the Chinese have a tendency to "downwardly" state their social status cross-sectionally, overall, our results suggest a modified version of the "R\&R blend" as best describing SSS in China and its recent changes. Changing economic conditions have explanatory power in understanding the evolution of SSS in China, but there remains still a Chinese tendency to "downwardly bias" their SSS.

\section{REFERENCES}

Adair, Stephen, 2001, Immeasurable differences: A critique of the measures of class and status used in the general social survey." Humanity and Society, 25: 57-83.

Adler, Nancy. E., Epel, Elissa. S., Castellazzo, Grace., and Ickovics, Jeannette. R. 2000. Relationship of subjective and objective social status with psychological and physiological functioning: preliminary data in healthy white women. Health Psychology, 19(6): 586-592.

Andersen, Robert, and Josh Curtis, 2012,The Polarizing Effect of Economic Inequality on Class Identification: Evidence from 44 Countries, Research in Social Stratification and Mobility, 30(1):129-141;

Appleton, Simon, and Lina Song, 2008, Life Satisfaction in Urban China: Components and Determinants. World Development. 36(11):2325-2340.

Bartolini, Stefano, and Francesco Sarracino 2014, The dark side of Chinese growth: Explaining decreasing well-being in times of economic boom. MPRA Paper No. 57765

Bian, Yanjie, 2002, Chinese Social Stratification and Social Mobility. Annual Review of Sociology, 28:91-116.

Bian, Yanjie, and John Logan, 1996, Market Transition and Persistence of Power: The Changing Stratification System in Urban China.” American Sociological Review, 61(5):739-758.

Bian, Yanjie, and Li Lulu, 2013, The Chinese General Social Survey (2003-8), Chinese Sociological 
Review, 45(1):70-97.

Centers, Richard, 1949, The Psychology of Social Classes. Princeton: Princeton University Press.

Curtis, Josh, 2014, Social Mobility and Class Identity: The Role of Economic Conditions in 35 Societies. European Sociological Review, (R\&R) 2013

Easterlin, R. A., Morgan, R., Switek, M., and Wang, F. (2012). China's life satisfaction, 1990-2010. Proceedings of the National Academy of Sciences, 109(25):9775-9780

Evans, M.D.R., and Jonathan Kelley, 2004, Subjective Social Location: Data from 21 Nations, International Journal of Public Opinion Research, 16(1):3-38.

Evans, M.D.R., Jonathan Kelley, and Tamas Kolosi, 1992, Images of Class: Public Perceptions in Hungary and Australia, American Sociological Review, 57(4):461-482;

Xiaoguang Fan,and Chen, Yunsong, 2015, "Social Class Discordance in Contemporary China", Chinese Journal of Sociology(Chinese) 2015(4).

Gao, Yong, 2013, Why Has Status Identification Declined: On the Changes in the Basis of Status Identification", Chinese Journal of Sociology (Chinese), 2013(4)

Griffin, K., and R. Zhao, 1993, eds., The Distribution of Income in China, Basingstoke: Macmillan, 1993;

Guest, Avery, 1974, Class Consciousness and American Political Attitudes, Social Forces, 52:496-510;

Hamamura, Takeshi, 2012, Social Class Predicts Generalized Trust But Only in Wealthy Societies, Journal of Cross-Cultural Psychology, Vol. 43(3): 498-509.

Hodge, Robert and Donald Treiman, 1968, Class identification in the United States, American Journal of Sociology, 73:535-547.

Hout Michael, 2008, How Class Works in Popular Conception: Most Americans Identify with the Class Their Income, Occupation, and Education Implies for Them, in Annette Lareau and Dalton Conley, eds., Social Class: How Does It Work?, New York: Russell Sage Foundation, Chapter 2.

Jackman, Mary R., and Robert W. Jackman, 1983, Class Awareness in the United States. Berkeley: University of California Press.

Kelley, Jonathan, and M. D. R. Evans, 1995, Class and Class Conflict in Six Western Nations. American Sociological Review, 60:157-177.

Kikkawa, Takamaro, 2000, Changes in the determinants of class identification in Japan, International Journal of Sociology, 30(2):34-51.

Kim, J.H., Lee, S.G., Shin, J., and Park, E.C. 2014. Impact of the gap between socioeconomic stratum and subjective social class on depressive symptoms: Unique insights from a longitudinal analysis, Social Science \& Medicine, 120: 49-56.

Li, Peilin, Yi Zhang, Yandong Zhao, and Dong Liang, 2005, Social Conflict and Class Consciousness: Research on the problem of Social antagonisms in contemporary China (Chinese). Beijing: Social Sciences Document Publishing House

Liu, Xin, 2001, Strata Consciousness in Transition-Era Urban China, Sociological Studies(Chinese), no.3.

Lopreato, Joseph, and Lawrence Hazelrigg, 1972, Class Conflict and Mobility. San Francisco: Chandler.

Moorhouse, H. F, 1976, Attitudes to class and class relationships in Britian, Sociology, 10(3):469-496.

Morris, Richard T., and Raymond J. Murphy, 1966, A Paradigm for the Study of Class Consciousness, Sociology and Social Research, 50:297-313.

Nam, EunyYoung, 2013, Social Risks and Class Identification after the Financial Crisis in Korea, Development and Society, 42(2): 237-262.

Nee, Victor, 1996, The Emergence of a Market Society: Changing Mechanisms of Stratification in China. American Journal of Sociology, 101(4):908-949;

Nee, Victor, and Rebecca Matthews, 1996, Market Transition and Societal Transformation in Reforming State Socialism. Annual Review of Sociology, 22:401-435.

Goldman, Noreen, Jennifer Cornman, and Ming-Cheng Chang. 2006. Measuring Subjective Social Status: A Case Study of Older Taiwanese. Journal of Cross-Cultural Gerontology, 21:71-89.

Oddsson. Gudmundur Aevar, 2010, Class awareness in Iceland," International Journal of Sociology 
and Social Policy, 30(5/6):292-312.

Parish,William, and Ethan Michelson, 1996, "Politics and Markets: Dual Transformations." American Journal of Sociology, 101:1042-1059;

Piff, Paul K., Michael W. Kraus, Stephane Cote, Bonnie Hayden Cheng, and Dacher Keltner, 2010, Having Less, Giving More: The Influence of Social Class on Prosocial Behavior, Interpersonal Relations and Group Processes, Vol2 99(5): 771-784.

Piff, Paul L., Daniel M. Stancato, Stephane Cote, Rodolfo Mendoza-Denton, and Dacher Keltner, 2011, Higher social class predicts increased unethical behavior, Proceedings of the National Academy of Science of the United States of America, Vol. 109(11): 4086-4091.

Shirahase, Sawako, 2010, Japan as a stratified society: With a focus on class identification," Social Science Japan Journal, 13(1):31-52

Singh-Manoux, A., Adler, N. E., \& Marmot, M. G. 2003. Subjective social status: Its determinants and its association with measures of ill-health in the Whitehall II study. Social Science \& Medicine, 56(6):1321-1333.

Singh-Manoux, A., Marmot, M.G. \& Adler, N.E. 2005. Does subjective social status predict health and change in health status better than objective status? Psychosomatic Medicine, 67:855-861.

Stouffer, Samuel, A., E. A. Suchman, Lois C. de Vinney, Shirley A. Star and Robin M. Williams Jr, 1949, The American Soldier: Adjustment During Army Life. Princeton: Princeton University Press

Surridge, Paula, 2007, "Class belonging: A quantitative exploration of identity and consciousness," British Journal of Sociology, vol.58(2):207-226.

Walder, Andrew G., 1986, Communist Neo-Traditionalism: Work and Authority in Chinese Industry. Berkeley and Los Angeles: University of California Press, 1986.

Wang, Weidong, 2011, Chinese General Social Survey 2003-2011. www.uchicago.cn/wp-content/uploads/2011/05/Weidong-Wang.pdf

Woelfel, Joseph, and Archibald O. Haller, 1971, Significant others, the self-reflexive act, and the attitude formation process. American Sociological Review, 36(1):74-87.

Wooldridge, Jeffrey M. 2002. Econometric Analysis of Cross Section and Panel Data. Cambridge, Massachusetts. London, England: TheMIT Press.

Wright, Erik Olin, 1985, Classes. London: Verso.

Wright, Erik Olin, and Joachim Singelmann, 1982, Proletarianization in the Changing American Class Structure, American Journal of Sociology, vol.88:196-209.

Wu, Xiaogang, 2002, Work Units and Income Inequality:The Effect of Market Transition in Urban China. Social Forces, 80(3) 69-99.

Wu, Xiaogang, and Donald Treiman, 2004, The Household Registration System and Social Stratification in China, 1955-1996. Demography, 41(2):363-384;

Xie, Yu, and Xiaogang Wu, 2008, Danwei Profitability and Earnings Inequality in Urban China. The China Quarterly, 195(1):558-581.

Xie, Yu, and Emily Hannum, 1996, Regional Variation in Earnings Inequality in Reform-Era Urban China. American Journal of Sociology, 101(4):950-992.

Zang, Xiaowei, 2012, Scaling the Socioeconomic Ladder: Uyghur Perceptions of Class Status in Urümchi. Journal of Contemporary China 21/78: 1,029-43.

Zhou, Baohua, 2011. New Media Use and Subjective Social Status. Asian Journal of Communication, 2:133-149.

Zhou, Xueguang, 2000, Economic Transformation and Income Inequality in Urban China. American Journal of Sociology, 105(4):1135-1374.

\section{ENDNOTES}

1 There has been an impressive accumulation of studies focusing on social stratification and mobility in post-reform China (Walder, 1986; Nee and Matthews, 1996; Bian and Logan, 1996; Griffin and Zhao, 1993; Nee, 1996; Parish and Michelson, 1996; Xie and Hannum, 1996; Zhou, 2000; Wu, 2002; Wu and Treiman, 2004; Xie and $\mathrm{Wu}, 2008$, to name a few). See Bian (2002) for a thorough review.

2 The overall response rate of both the CGSS and CSS average around 60 percent (Wang 2011;Bian and Li 
2013).

${ }^{3}$ This is comparable to item non-response of similar survey questions in the US (Hout, 2008).

4 All waves sampled both rural and urban China, except the 2003 CGSS which only sampled urban residents. In later analyses, we include the 2003 CGSS to increase waves for time trend analysis. In sensitivity tests, however, we exclude it to see if our results are robust.

5 Weights are calculated as follows, taking the year of 2010 as an example: First, a household weight (HWT) equal to the ratio of the number of adults in the household to the mean number of adults per household (estimated separately for the urban and rural samples) was computed, an appropriate weight to use when we analyze the urban and rural samples separately. Second, since in 201049.68 per cent of the population that year (1.339 billion) lived in urban areas, a population weight (PWT) was computed separately for the urban and rural samples. For the urban population, PWT $=[1.339$ billion*0.4968 /urban sample size $] * H W T$; for the rural population, $\mathrm{PWT}=[1.339 \text { billion*0.50.32/rural sample size }]^{*}$ HWT. Finally, weights are then normalized to the original sample size of 2010: WEIGHT1=PWT/mean (PWT). Since the 2010 population is 1.339 billion and we have a sample of 11,730, the weights of cases in 2010 are further corrected by WEIGHT2=WEIGHT $1 * 1.339 / 11,730$. Then weights are finally normalized to the original overall sample size from 2003 to 2010: WEIGHT=WEIGHT2/mean(WEIGHT2). Similar method can be referred in Wu and Treiman (2004).

6 The use of a 10-scale has been used elsewhere e.g. Evans and Kelley (2005), Adler et al. (2000), Goodman et al. (2001), and Goldman et al. (2003).

7 Specifically, we recoded top 10 and 9 as upper stratum, 8 and 7 as upper middle, 6 and 5 as middle, 4 and 3 as lower middle, and 2 and 1 as lower stratum. For the 2008 and 2011 waves, where we have overlap in the two measures, we compared the recoded status distribution of CGSS with its counterpart of CSS, and found that the status distributions are reassuringly very close.

${ }^{8}$ Including respondents who never worked and setting work variables to zero, as well as focusing only on respondents employed at the time of the survey does not alter qualitative findings. We thank an anonymous reviewer for pointing to the issue of sample selection.

${ }^{9}$ For those who are retired the ISEI is computed based on their last job.

${ }^{10}$ We conducted the parallel test and found that the precondition of fitting an OLogit model is satisfied.

${ }_{11}$ To save space we do not report the regression results here but they are available upon request. Specifically, we also fitted: (1) multi-level models treating provinces as the higher level and observations at the lower level; (2) a multi-level ordered logistic model; (3) all models but excluding the 2003 wave, since it sampled only urban residents; and (4) other models on sub-samples such as wave-specific samples, CGSS samples, CSS samples, urban samples, and rural samples. All in all, although not reported here, the similar results of these tests show results consistent with the main findings reported here.

12 For instance, the mean of subjective social status in China is also 2.32 according to the World Values Survey 2010-2014, and is 2.44 according to International Social Survey Program 2009 (ISSP; Social Inequality IVISSP 2009 ZA5400).

13 We define social groups by gender, age (17-35,36-45,46-55, older than 55), marital status (single, divorced/widowed, married), residential status (rural, urban, rural-urban migrants), CCP membership, education (tertiary, senior high school, junior high school, primary school and below), income (4 quartiles), and occupational prestige score (4 quartiles).

${ }^{14}$ We use 2006 as the base year since the 2003 sample only sampled urban residents, but comparing the urban 2003 sample with the 2012 sample restricted to only urban residents yields similar results.

${ }^{15}$ We would like to thank an anonymous reviewer for making this suggestion. 


\section{TABLES}

Table 1. Data from 10 Waves of CGSS and CSS, 2003-2012

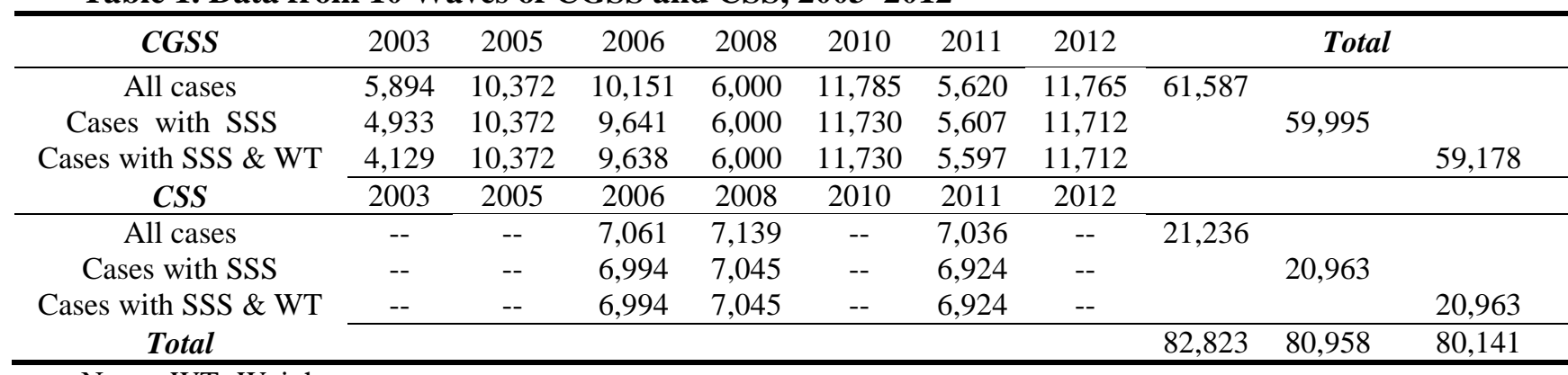

Notes: WT=Weight

Table 2. Weighted Descriptive Statistics for Variables Used in Models of SSS in China, 2003-2012

\begin{tabular}{|c|c|c|c|}
\hline \multicolumn{2}{|c|}{ Variables } & \multirow[t]{2}{*}{ Proportion } & \multirow{2}{*}{$\begin{array}{l}\text { Mean (s.d.) } \\
2.34(.910)\end{array}$} \\
\hline SSS & & & \\
\hline & Upper $=5$ & $0.82 \%$ & \\
\hline & Upper Middle=4 & $6.08 \%$ & \\
\hline & Middle $=3$ & $40.63 \%$ & \\
\hline & Lower Middle $=2$ & $31.19 \%$ & \\
\hline & Lower $=1$ & $21.29 \%$ & \\
\hline \multirow[t]{3}{*}{ Work Status } & Unemployed & $14.48 \%$ & \\
\hline & Employed & $74.76 \%$ & \\
\hline & Retired & $10.76 \%$ & \\
\hline \multirow{2}{*}{ Residential Status } & Rural residents & $51.14 \%$ & \\
\hline & Urban residents/migrants & $48.86 \%$ & \\
\hline \multirow[t]{3}{*}{ Marital Status } & Married & $88.43 \%$ & \\
\hline & Single & $5.26 \%$ & \\
\hline & Divorced/widowed & $6.31 \%$ & \\
\hline Male $=1$ & & $50.0 \%$ & \\
\hline CCP Member $=1$ & & $10.0 \%$ & \\
\hline Age & & & $45.42(14.06)$ \\
\hline Years of Schooling & & & $8.41(4.20)$ \\
\hline ISEI & & & $34.66(15.35)$ \\
\hline Family Annual Inc & & & $42,662(120,168)$ \\
\hline
\end{tabular}

Notes: Percentages for categorical variables and means for continuous variables are reported; mean score of SSS is also shown; numbers in parentheses are standard deviations. 
Table 3. OLS and OLogit Models of SSS in China, 2003-2012

\begin{tabular}{|c|c|c|c|c|}
\hline & Model 1 & Model 2 & Model 3 & Model 4 \\
\hline & OLS & OLS & OLogit & OLogit \\
\hline \multicolumn{5}{|l|}{ Individual Attributes } \\
\hline Household income (HI) & $.195 * * *(.008)$ & $.202 * * *(.009)$ & $.076 * * *(.003)$ & $.077 * * *(.003)$ \\
\hline Schooling years (SY) & $.020 * * *(.003)$ & $.019 * * *(.003)$ & $.006 * * *(.0008)$ & $.006 * * *(.0008)$ \\
\hline Occupation (ISEI) & $.006 * * *(.006)$ & $.006 * * *(.01)$ & $.002 * * *(.0002)$ & $.002 * * *(.0002)$ \\
\hline Age & $.003 * * *(.001)$ & $.003 * * *(.01)$ & $.001 * * *(.0002)$ & $.001 * * *(.0002)$ \\
\hline Male & $-.089 * * *(.009)$ & $-.089 * * *(.001)$ & $-.031 * * *(.003)$ & $-.031 * * *(.003)$ \\
\hline CCP membership & $.089 * * *(.012)$ & $.096 * * *(.013)$ & $.027 * * *(.004)$ & $.030 * * *(.004)$ \\
\hline \multicolumn{5}{|l|}{ Marital status } \\
\hline Divorced/Widowed & $-.094 * * *(.019)$ & $-.093 * * *(.019)$ & $-.032 * * *(.007)$ & $-.031 * * *(.007)$ \\
\hline Single & $-.008(.023)$ & $-.014(.024)$ & $-.003(.008)$ & $-.006(.008)$ \\
\hline \multicolumn{5}{|l|}{ Work status } \\
\hline Employed & $.128 * * *(.012)$ & $.125 * * *(.013)$ & $.043 * * *(.0042)$ & $.042 * * *(.004)$ \\
\hline Retired & $.088 * * *(.014)$ & $.089 * * *(.015)$ & $.027 * * *(.005)$ & $.027 * * *(.006)$ \\
\hline Urban resident & $-.238 * * *(.024)$ & $-.242 * * *(.023)$ & $-.090 * * *(.008)$ & $-.092 * * *(.008)$ \\
\hline HI* Urban resident & $.041 * *(.011)$ & $.040 * *(.01)$ & $.029 * * *(.005)$ & $.033 * * *(.004)$ \\
\hline SY* Urban resident & $-.003(.002)$ & $-.003(.003)$ & $-.002 *(.001)$ & $-.002 *(.001)$ \\
\hline ISEI * Urban resident & $-.001(.001)$ & $-.001(.001)$ & $-.0006 *(.0003)$ & $-.0007 *(.0003)$ \\
\hline Project Dummy & $-.082 * * *(.026)$ & $-.023(.019)$ & $.030 * * *(.009)$ & $.008(.006)$ \\
\hline Linear Year & --- & $.014 * * *(.004)$ & --- & $.008 * * *(.001)$ \\
\hline HI * Linear Year & --- & $-.010 * * *(.002)$ & --- & $-.003 * * *(.006)$ \\
\hline SY * Linear Year & --- & $-.001 *(.0004)$ & --- & $-.002 *(.001)$ \\
\hline ISEI * Linear Year & --- & $-.0001(.001)$ & --- & $.00004(.00004)$ \\
\hline Province Dummies & YES*** & YES*** & YES*** & YES*** \\
\hline Year Dummies & YES*** & --- & YES*** & --- \\
\hline Cut-off Point 1 & --- & --- & $-1.015 * * *(.099)$ & $-.647 * * *(.073)$ \\
\hline Cut-off Point 2 & --- & --- & $.568 * * *(.102)$ & $.922 * * *(.068)$ \\
\hline Cut-off Point 3 & --- & --- & $3.296 * *(.104)$ & $3.632 * *(.073)$ \\
\hline Cut-off Point 4 & --- & --- & $5.541 * * *(.112)$ & $5.874 * * *(.103)$ \\
\hline Constant & $2.113 * * *(.046)$ & $2.019 * * *(.032)$ & --- & --- \\
\hline R-Squared/PseudoR-Squared & $13.75 \%$ & $12.63 \%$ & $6.24 \%$ & $5.77 \%$ \\
\hline $\mathrm{N}$ (observations) & 68,054 & 68,054 & 68,054 & 68,054 \\
\hline
\end{tabular}

Notes: (1) Estimations are based on weighted data; robust standard errors adjusted for clustering on provinces are shown in parentheses. (2) Results from Ologit models are average marginal effects predicting the probability of not reporting the lowest subjective status.(3) Reference categories: female, non-CCP membership, married, unemployed, no perceived-mobility; project CGSS; year 2003; Beijing. (4) *** p<0.001, ** p<0.01, * p $<0.05$ (two-tailed tests) 
Table 4. Oaxaca-Blinder Decomposition of Change in Mean SSS in China, 2006-2012

\begin{tabular}{ll}
\hline Mean SSS 2006 & $2.079 * * *(.026)$ \\
Mean SSS 2012 & $2.419 * * *(.035)$ \\
Difference & $.339 * * *(.028)$ \\
Total "endowments effect" & $.213 * * *(.024)$ \\
Total "returns to endowments & $.127 * * *(.035)$ \\
effect" & \\
& \\
Contribution to the "endowments & \\
effect" of: & $.215 * * *(.017)$ \\
$\quad$ Household income (HI) & $.002(.006)$ \\
$\quad$ Schooling years (SY) & $.007(.005)$ \\
$\quad$ Occupation (ISEI) & \\
Contribution to "returns to & \\
endowments" of: & $.017 * *(.007)$ \\
$\quad$ Household income (HI) & $.006(.002)$ \\
Schooling years (SY) & $.004(.002)$ \\
$\quad$ Occupation (ISEI) & $-.006(.110)$ \\
$\quad$ Constant & 24,054 \\
N (observations) &
\end{tabular}

Notes: (1) Estimations are based on weighted data; robust standard errors adjusted for clustering on provinces are shown in parentheses. (2) The same controls in Table 3 Model 1 are entered into the model but omitted to save space. (3) Reference categories: female, non-CCP membership, married, unemployed, no perceived-mobility; project CGSS; year 2003; Beijing. (3) *** $\mathrm{p}<0.001, * * \mathrm{p}<0.01, * \mathrm{p}<0.05$ (two-tailed tests). 


\section{FIGURES}

Figure 1. Pie Chart of SSS in China, 2003-2012

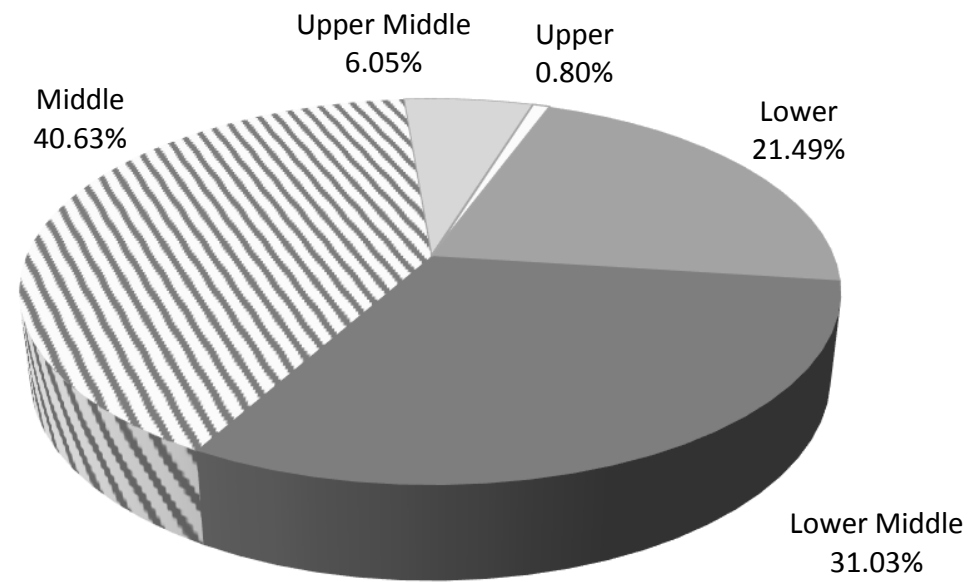

Figure 2. Distributions of SSS in China by Survey Year

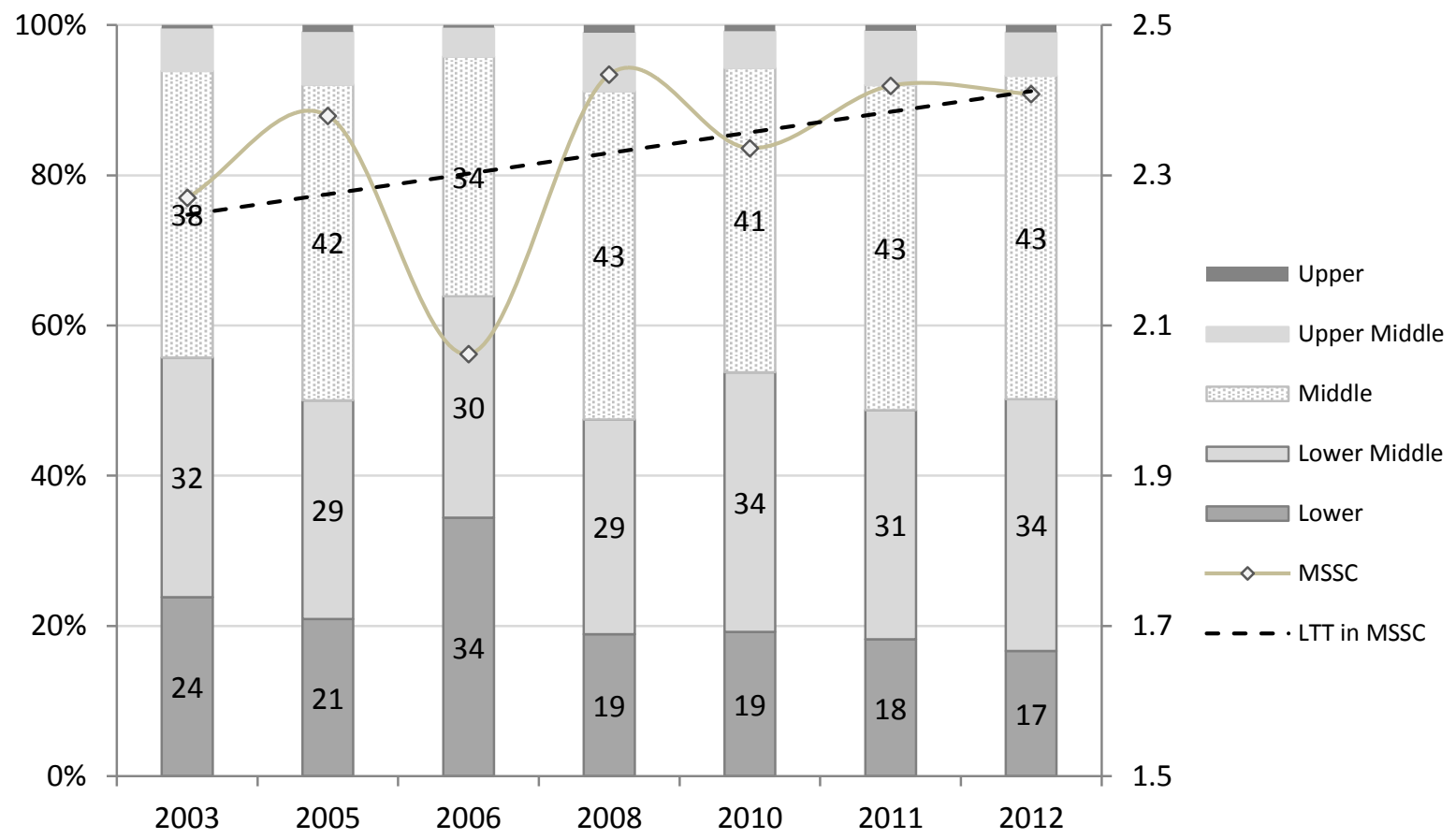

Notes: Distribution of SSS (left scale) ; Mean score (right scale) MSSC $=$ Mean of SSS $;$ LTT $=$ Linear Time Trend 
Figure 3. Liner Time Trends in SSS by Social Group and Survey Year
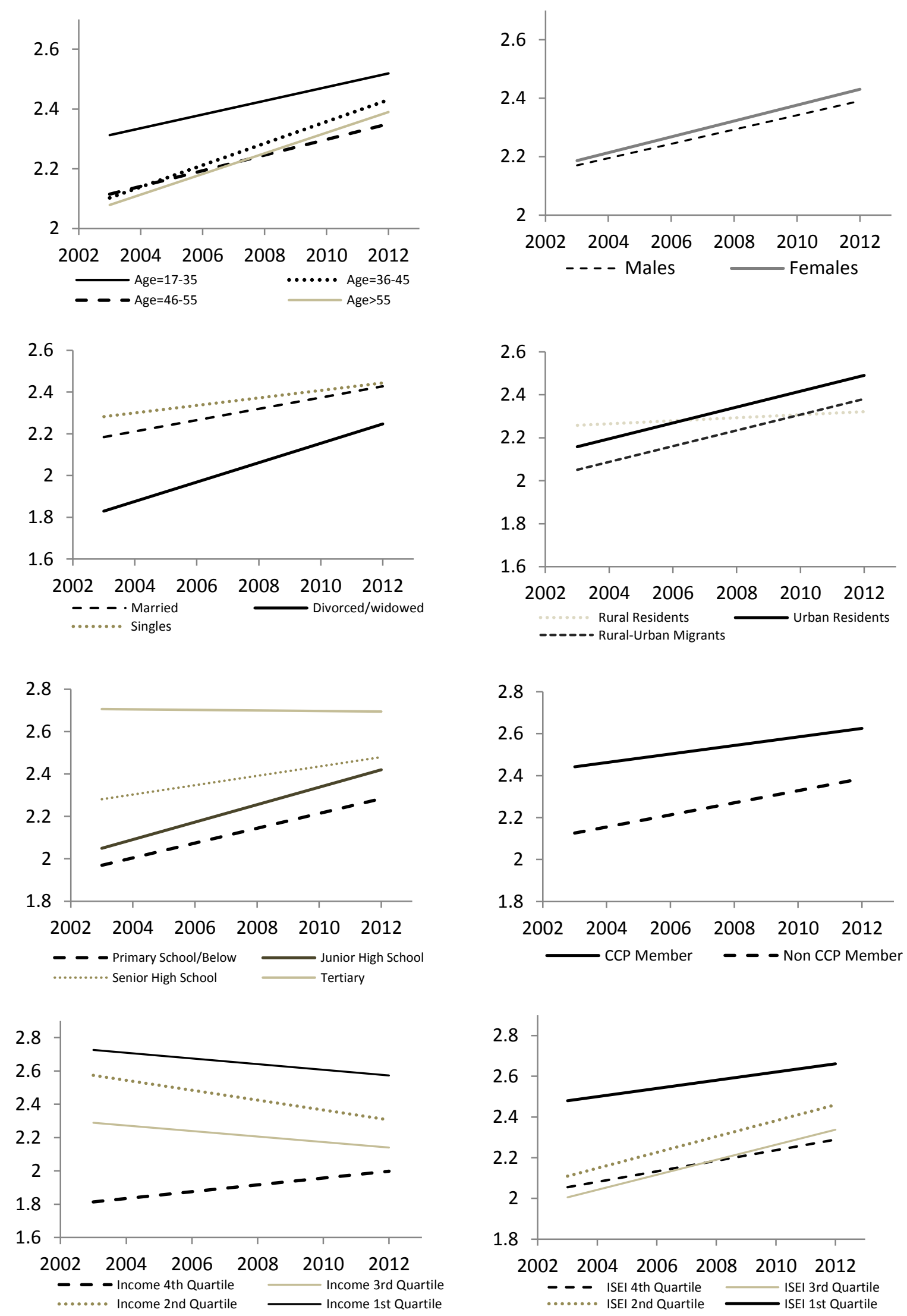

Notes: ISEI is the International Social Economic Index. Income refers to household income. 